\title{
Serious Games - Communication Aspects of VR Cadet Training Information Model
}

\author{
JADRANKO TUTA \\ Department of Media and Communication \\ University North \\ Trg dr. ŽarkaDolinara 1, Koprivnica \\ CROATIA
}

\author{
LJERKA LUIĆ \\ Department of Media and Communication \\ University North \\ Trg dr. ŽarkaDolinara 1, Koprivnica \\ CROATIA
}

\begin{abstract}
The paper deals with the communication aspects of training cadets using serious virtual reality games and is an initial step in defining the framework of a standard VR information model in the military training aimed at defining additional categories of data that do not appear in any of the existing information models. The first part of the paper deals with the conceptual definition of serious games, and in the following, the process of simulating serious games in training cadets is elaborated. The research problem is primarily focused on examining the communication aspects of a theoretically designed serious game and its effects. For the purpose of designing the VR information model, a pilot survey was conducted with cadets of the Croatian Military Academy, using 113 questionnaires, with 113 of them from all generations of training. The obtained results confirmed the initial assumption about the correlation of serious game and simulation game in the domain of virtual reality. In addition, the results indicate a potential correlation between the frequency of performing a particular type of serious play and the selection of military service. All of the above implies the need for further systematic research into the subject matter.
\end{abstract}

Key-Words: communication, virtual reality, serious games, e-learning, cadet training, information model

Received: December 2, 2019. Revised: May 24, 2020. Accepted: May 28, 2020. Published: June 4, 2020.

\section{Introduction}

By Virtual reality (VR) we mean computer simulations that should create a sense of being present in a virtual environment [1]. These include simulation and real-time interactions across multiple sensory channels [2]. Sensory modalities can be visual, auditory, haptic, smell (odor) and taste [1]. The concept of virtual reality has existed for a long time.For a clearer picture of virtual reality, it is crucial to cite the division that has been defined in the research and resolution of the reality question. There are three major types of virtual reality divisions for which some of the main characteristics are listed:

- Virtual Reality, VR;

- Augmented Reality, AR;

- Mixed Reality, MR.

If we look at virtual reality, we can find in it a new, virtual world that we see with the help of specific head mounted devices (like Oculus Rift HTC Vive, OSVR, and others) and, if necessary, use accessories to operate the game console.Furthermore, augmented reality is at any place with the user staying in the real world which is added with digital content. On the one hand augmented reality exposes digital image in the real world and on the other hand, mixed reality shows digital objects housed in the real world. It also allows to tour objects in real space and view objects from all angles [3]. Today VR has numerous applications in real life in the following domains: healthcare, military technologies, education, virtual heritage, design and architecture, entertainment and marketing [1]. Military organizations have been investing in VR technology since its inception, as it has been used as simulation training to acquire various military skills [1]. These types of simulations are useful because they reduce exposure in an unsafe environment and can increase concealment [4]. However, training is just one of the many areas where VR technologies are applied. Another example of very useful utilization of VR in a therapy of military personnel diagnosed withposttraumatic stress disorder (PTSD) and other cognitive disorders [5].

In this regard, this paper seeks to explore new technologies that will enhance military education which is highly complex and demanding, and each part of education seeks to approach a specific realistic task. The idea of military education is in fact to bring all its requirements as close as possible to actual tactical situations within the combat area. 
Often, such ventures often involve an enormous amount of expense, and are sometimes a great danger to the trainers themselves and the trainees. This paper discusses the application of augmented and virtual reality within the military domain. As such, it enables tactical situations to be created in a very simple way, thereby raising the level of security to the highest level.

The paper is structured as follows. First, the theory of augmented and virtual reality is elaborated, technology advantages and disadvantages will be presented, and its general utilization within military domain is described. After that, the idea of AR and VR prototypes developed specifically for the purpose of the research performed within Croatian Military Academy (CMA) "Dr. Franjo Tuđman" is presented with obtained prototype evaluation results. Paper discusses potential of AR and VR prototype as a reference for creating virtual simulations and future solutions in AR technology that could be implemented within cadet education and then within the armed forces trainings.

\section{Formulation problem}

Modern simulations are playful, random, dazzling, fast, fictitious and constantly changing. They suppress the possibility of display and the relevance of simulation to the real world in complete contrast to the aspirations of simulations and games or the tradition of war games. Modern computer war games are enticing and compelling enough that we would be willing to swap their interfaces for reality and spend some time alone or in the company of thousands of other networked warriors. In such games, reality is not represented in a virtual way (virtual reality), but the real and authentic is represented by the imaginary world of the game, creating virtual reality. Persuasive virtual worlds, created to entertain players and bring profits to creators, are, for the most part, far from historical reality and actual wars. [6] Every video game, including every serious game, has its advantages and disadvantages. What makes a serious game acceptable for creation and use is how many advantages outweigh the disadvantages and what exactly is required of the game requested.The same applies to simulations. With the prevalence of "undemanding" games and new devices (smartphones, tablets, different types of consoles), a series of serious games are quickly established for different types of users (students, workers, soldiers, cadets, etc.), applications / goals (teaching, training , advertising, politics, etc.) and the implementation of different genres (adventure, action, strategy, etc.) [7] Simulation games provide the opportunity to teach on new equipment and doctrine at no great cost even when equipment is unavailable. Scenarios are easily adapted to training requirements, without losing the experience of stress in stressful situations, and simulation games allow different units to be trained under the same conditions and standards, as well as combined,cross-border and multi-branchoperations.

It is important to know that incorporating simulations into cadet training is a must, and it is possible to learn. Improper use of simulation and of possibilities are a disadvantage that depends on the instructor (trainer) and not on the simulation. The notion of "getting caught in a warrior's trap" is a disadvantage of using simulations that is hard to avoid because the soldier is used to winning, which is not the purpose of the simulation. The honesty and fairness of the trainees in conducting the training simulations are extremely important because otherwise they negate all training results. The most important example of an irreversible drawback is the limitation in simulating psychological effects, which is known as the great limitation of task success. [8], [9]

\section{A theoretically designed serious game}

In order to solve the problem, a serious game called "Choosing directions for future team commanders" was theoretically designed. What makes a military team good? Originally it was cohesion, the ability of people to work together in all circumstances that may arise. Then, just knowing each team member what his or her job is and what the other team members are doing. Knowledge of the task is also an important factor in a good military team. But one of the most important factors and people on that team is their commander, their leader.

\section{1 "Choosing directions for fu ture team commanders"}

The commander of the military team must be familiar with his / her tasks, all the tasks of his / her team, familiarize the members with the task as well as achieve cohesion within the team. In other words, he must know everything that his people, even more than that, because it is important for him to make important decisions. It is the commander who is responsible for the lives of each team member and all their actions. That is why one has to put the right man in such a position.

The main objective of this game is familiarize the users of what it means to be an officer, that is, the commander of a military team, of a particular gender or service. Other goals are to familiarize the player with vehicles and equipment, the tasks of 
individual team members, and the tasks of the gender itself. The cadet service at the CAF is a service that prepares new officers, junior lieutenants, for future commanders of military teams. That is why cadets need to be identified and taught at the outset, which means being the commander of military teams of certain branches and creating a good commander that people will want to follow.

The question of why use a serious game can be answered by showing the benefits it brings with you, such as being able to use it anytime, anywhere without the need for extensive logistical needs, enhancing people's understanding without spending a great deal of time and resources, an always-ready reusable tool, avoiding the need for everyone to be present at the same time as presentations or visits to other barracks, allowing the speed of performance to be determined independently.

\subsubsection{Characteristics of games}

Serious play seeks to increase player motivation and thus the level of commitment to learning matter by using, to most users of familiar concepts. Each game is considered to have certain characteristics: fun (activity is chosen because of the leisurely nature of the character), separation (limited time and place), uncertainty (unpredictable outcome of the activity), unproductive (participation does not achieve anything useful), existence of rules (the game contains rules that are different from everyday life), fiction (awareness of different reality). However, of all these characteristics, Erenli, from the University of Applied Sciences in Vienna, in his report entitled "The Impact of Education: Recommendation of Educational Scenarios" dismisses the term "unproductive" for all games used for educational purposes [10]. By rejecting unproductivity from the characteristics of educational games, the other characteristics are rounded off with a single purpose - the main key to such games is to learn something from them. And that is why they cannot be unproductive.

\subsubsection{Users and mode of use}

The users of the game proposal were initially cadets after completing their first year of study at the Croatian Military Academy, before selecting a further orientation, and later on conscripts, basic officer training and other active military personnel. Depending on the needs of the CAF, orientations for the direction of Military Engineering may be: Armor, Artillery, Engineering, Technical Services, Transportation Services, Infantry, Communications, Observation and Guidance, Air Defense, and Nuclear Biological Chemical Defense; while in the direction of Military Command and Command are infantry, military police and military intelligence. However, after the first year, cadets are not fully familiar with military backgrounds and services, so they don't really know what it means to be an officer of a certain gender. This serious game should clarify and portray these genera in the most real light of what cadets can expect after the graduation. The intended way to use this serious game is on PCs or laptops in combination with VR glasses (Virtual Reality), primarily OCULUS Rift glasses with consoles. stvarnost).

\subsubsection{Game Scenario}

The game has three main menus. Each menu has four or five levels, and each level is one branch. Levels can be divided into three sub-levels, namely scenarios and work points that a player needs to go through to move to the next level. The first post is of an informative type and describes in more detail the divisions within the branches. The second duty point is in charge of vehicles and equipment, and the third duty point is occupied with human resources. In order to get past the work point, one has to familiarize himself with all the parts of each work point and get a sign (star, bullet, target, key and symbol of danger) marking the passage of the scenario. The goal of each level is to hit the target at the end of each level by shooting at the tank and thus finishing the level. When the cadet starts the game, a home screen appears with a scene of slowly approaching the military base. Arriving at the entrance to the base will say "WELCOME" as a sign of successful entry into the game. Then the welcome sign is replaced with the game title and three menus are added below it. Using consoles, we get a display of the hands holding the guns we use as a way to enter menus, that is, instead of pushing the cursor on personal computers. One should be aware that this is a theoretical game. The focus of the game is on the Croatian Army, and in later versions Navy and Air Force branches can be added.

The first menu is "COMBAT SUPPORT BRANCH". Activities are performed by firing. The firing arm is not important because it can be fired with both but it is not possible to shoot at the same time with both hands. "Shooting" in the direction of the menu twice opens up options consisting of five types of combat support, namely: engineering, nuclear biological and chemical defense (NBKO), communications, surveillance and guidance, and military police.

The second menu is "COMBAT SUPPORT" "Shooting" in his direction expands the menu to options of four combat arms: armor, artillery, infantry and air defense. 
The third menu is "SERVICE" with its five options: technical, intendant, construction, health and transport. Technical service is the fifth orientation option in the "SERVICES" menu. Doubleclicking it opens a new window where, just like in the previous examples, a pontoon bridge can be seen in the background, with the tank in which the player should enter, and then "lead" to the first operating point. Sitting in a tank gaze changes to one seen from a driver's position. It is only possible to return to the main menu before entering the tank. Once it enters the tank one has to reach the end of this part of the game to return to the menu. The technical service is not combat-oriented. In the first point,"TECHNICAL SERVICE SPECIALIZATIONS", all divisions of the technical service can be seen, namely: armaments, moto-technique, classic ordnance, fuels and lubricants, marine propulsion systems, marine electrotechnical systems, marine electronic systems, aircraft and engine, aeronautical weapons, aeronautical instruments, radio and electronics, missiles and rocket systems, information-communication systems and radar systems. This division is made in the form of five boxes located in a meadow. The technical service specializations window pops up by clicking on each box. The first contains weapons, moto-technique, classic ordnance and fuels and lubricants. The other is marine propulsion systems, marine electrical systems and marine electronic systems. The third is aircraft and engine, aeronautical weapons and aviation instruments. Radio and electronics, information-communication systems and radar systems are in the fourth box, and in the last, the fifth one, there are missiles and rocket systems. The user, after inquiring about all the specialties, wins the first key needed to continue the game and returns to the tank, proceeding to the next item. Entering the tank again opens a new window called "DOCUMENTATION" and refers to the necessary documents that one commander needs to know how to complete. All documents are stacked side by side and one click shows an enlarged view of the selected document. Reviewing all 13 documents, the second key is won and the view returns from the tank and moves towards the last operating point. The name of the third work item is "SCHEMATIC DOCUMENTATION", which refers to the merging of technical documentation that the user has gone through in the previous point and a schematic representation of logging of technical material for maintenance, admissions and movement through the technical workshop during maintenance, handed over to the user after completion of maintenance operational worker-technical documentation. Arriving at the tank to the operating point, a new window will open again showing the scheme and the boxes with the names TS- 1 to MP-10 written. Below the boxes is an index of abbreviations on the scheme. Pressing the box should merge it with the green geometric shapes on the diagram. If specified, the box remains in the schema, and if not, it remains in place.

\subsubsection{Pilot research}

For the purpose of developing a VR information model for cadet training, a pilot survey was conducted with cadets from the first, second, third and fourth years of the HVU (CMA). They wanted to learn about their experiences with virtual and augmented reality (VR / AR) technologies and playing serious games (OI). 113 cadets from all years and from both directions responded (VViU Military Command and Management and VI Military Engineering).

The survey included a total of 5 questions, on the topic of serious games. When asked, "Have you ever heard of the term 'serious games'?" as many as $61.1 \%$ of the cadets answered NO, which is not surprising since the concept was not often used in their previous education, much less in the education of cadets. The next question was related to the concept of gaming and the cadets' preference for playing computer games and contained a question about which games were in question. The most common answers were: League of Legends (LoL), God of War, Call of Duty (CoD), Counter Strike (CS), ARMA, Battelfield, World of Tanks (WoT). The third question was whether they had ever seen or played any simulations, to which the majority expected the answer was YES, as much as $68.1 \%$. JCATS, Virtual BattleSpace (VBS), Flight simulator, ARMA and Truck simulator answered the game's questions. Of all the above simulations, the JCATS and VBS responses are significant to the problem under study. When asked "Have you ever played or seen any simulations?" $47.8 \%$ of the cadets answered affirmative. When asked about serious games by the vast majority of cadets, $88.5 \%$ of them thought that a simulation game related to branch and service at the end of the first year of study could significantly help them choose a further direction.

\section{Related work}

\subsection{The application of Virtual Reality in military domain}

The Army is an institution that seeks to maintain preparedness and ability to act through the implementation of training, i.e. field training within 
all military branches. For the purpose of carrying out the training as successfully as possible, it is necessary to prepare and plan it in the best possible way in order to achieve expected training outcome.

Through the preparation phase, virtual simulations emerge, as well as other software systems that could be beneficial for a trainee to practice a certain activity. Within aviation, there are available simulators for military airplanes and helicopters, within the navy there are ships and submarines simulators, while within the ground forces there are simulators for anti-armor systems, tanks, combat and non-combat vehicles, and even simulators for various types of rifle and self-shotgun shooting [11]. Military simulators are very useful in training but also very expansive and with limited availability for trainees - they can be used within carefully planned and sufficiently frequent time slots.Virtual reality is taking up more and more space for military training and military exercises, which is being developed to better condition tactical military units. One example is the VirTra system [12], for developing tactical skills within the military and police. The simulator seeks to provide soldiers with the latest tactical operations that require rapid responses under high levels of stress. VirTra uses multiple platforms with different views that surround users and display specific tactical situations. It also provides more users. Depending on the complexity of the platform, the following version is available [12]:

- Virtra V-100 - shown in Figure 1, a singlescreen simulator that allows multiple soldiers training at the same time;

- VirTra V-180 - shown in Figure 2, the primary difference from the above-mentioned version is a 180-degree viewing angle that high-level sense of reality.

Virtual Reality Exposure Therapy (VRET) [13] is a virtual system in which users are put into a 3D environment staged as a real tactical situation. VRET was tested with Vietnam War veterans who were placed in a jungle area accompanied by helicopters and thus managed to reduce PTSD symptoms. The University of Southern California Institute for Creative Technology has developed Bravemind [14] as the type of VRET that really aims in suppressing PTSD. Their researchers concluded that younger soldiers are easier to accept this form of therapy, given that they went through $3 \mathrm{D}$ interfaces through video games. Virtualreality applications can be found within the Navy and Air Force branches. The Oculus Rift was used in the BlueShark project [15], which, with the help of VR glasses, provides a 3D view of the vehicle's environment, in this case the space around the ship, giving in this way a clear picture of enemy aircraft position, submarines, rockets, ships or torpedoes. US Navy's Office of Institute Creative Technology (ICT)at the University of Southern California (USC) participated on this project. VR is combined with the touch screen to simulate all the controls that the operator works with.
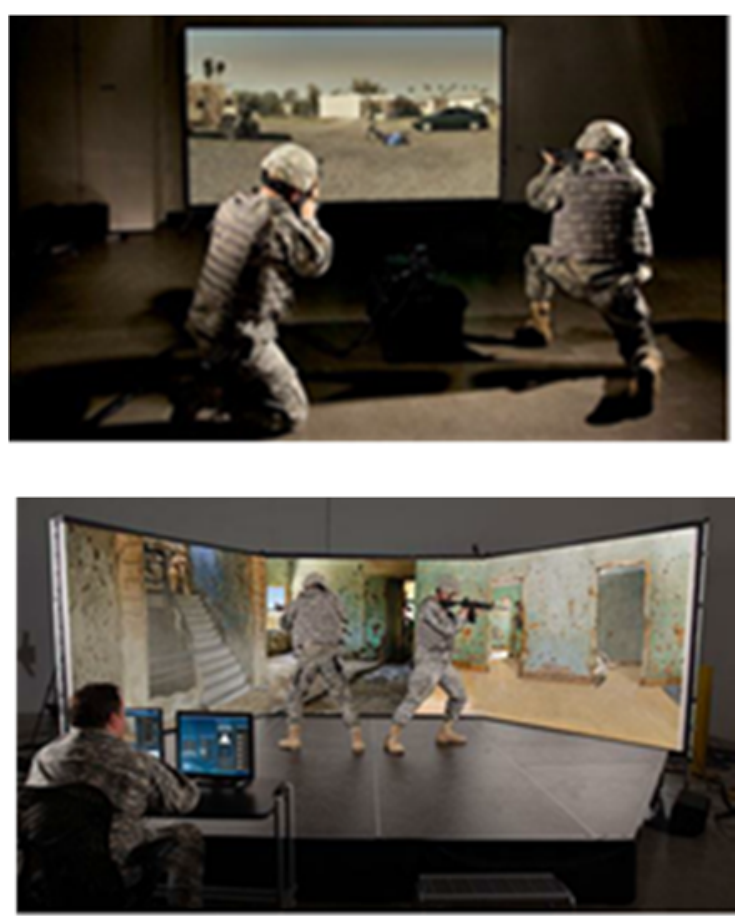

Fig. 1. VirTra V-100 (upper scene) and VirTra V-180 (lower scene), Source: https://www.virtra.com/overview-mil/

\subsection{Application of A ugmented Reality in military domain}

With the development of technology, augmented reality has found its place in the military domain as well. There are numerous military training solutions currently in use in this area, but as far no specific niche for this technology is defined.

The following examples show the existing AR solutions for conducting military training. The first of these is the STE - Synthetic Training Environment or a synthetic training environment which seeks to improve the readiness and ability of soldiers in various tactical environments. It is possible to perform various tactical tasks, that is, to create scenarios with the help of One World Terrain (OWT) [16] where 3D rendering imitates different entities that are placed in the real space.

\subsection{Simulators in the Croatian Armed Forces}

The Croatian Armed Forces use both ground and air force simulators, while naval simulators do not have any pronounced application within the CAF. The simulations seek to rehearse the unit before performing the exercise. In this way, they increase 
unit effectiveness and accomplishing the ultimate task.

Inside the Air Force there is a Full Mission Trainer cockpit installation Simulator A-10, which provides a $3 \mathrm{D}$ view of flight and aircraft operations in various situations. In this way, the crew gets a realistic picture of the flight and thus rehearses their actions.

The following simulators are used [11]:

- Simulator VS II - a simulator for training ground forces of the Czech army through the operation, operation and maintenance of combat vehicles such as the T-72 tank and the BVP combat vehicle;

- MUSE GCS UAV - simulator for simulation of work of front observers:

- CROTREND M1.1C and CROTREND M2.2C (FAUST) - trainers for the Malyutka anti-armor missile system (NATO name: AT-3 Sagger), Fagot (NATO name AT-4 Spigot) and Metis (NATO name AT-7 Saxhorn).

Moreover, there are so called actual simulations which emphasizing by the MILES 2000 system thatcame to life within the CAF. The system enables "simulation of a two-sided exercise by collecting data on the effects of direct firing on an individual, independent targets, weapons crews (combatants) and combat vehicles."

Therefore, each pedestrian and combat vehicle are assigned a control unit and laser transmitter that are connected to the central unit. In this way the real circumstances of using real-time weapons are simulated, taking into account the rate of fire of the weapon, the time intervals between shots, the time required to change tanks, etc. The MILES 2000 system consists of [11]:

- Combat vehicle systems;

- A system of independent goals;

- Crew Weapons System;

- Personal weapon systems;

- Dedicated weapons system;

- AAR system - post-action breakdown system;

- Surveillance devices and auxiliaries.

\section{Prototyping and evaluation of virtual application for military academy use}

A 2-year research was undertaken in which participated scientists and students from technical and computer field, and professionals and cadets from the military academy.

The main objective of the research was to investigate potential of utilization of VR and AR technology as well as the conceptual schemes serious games in the education of cadets. In order to perform the research, AR and VR prototype applications were developed [17]. VR prototype scenes are shown in the Figure 2.
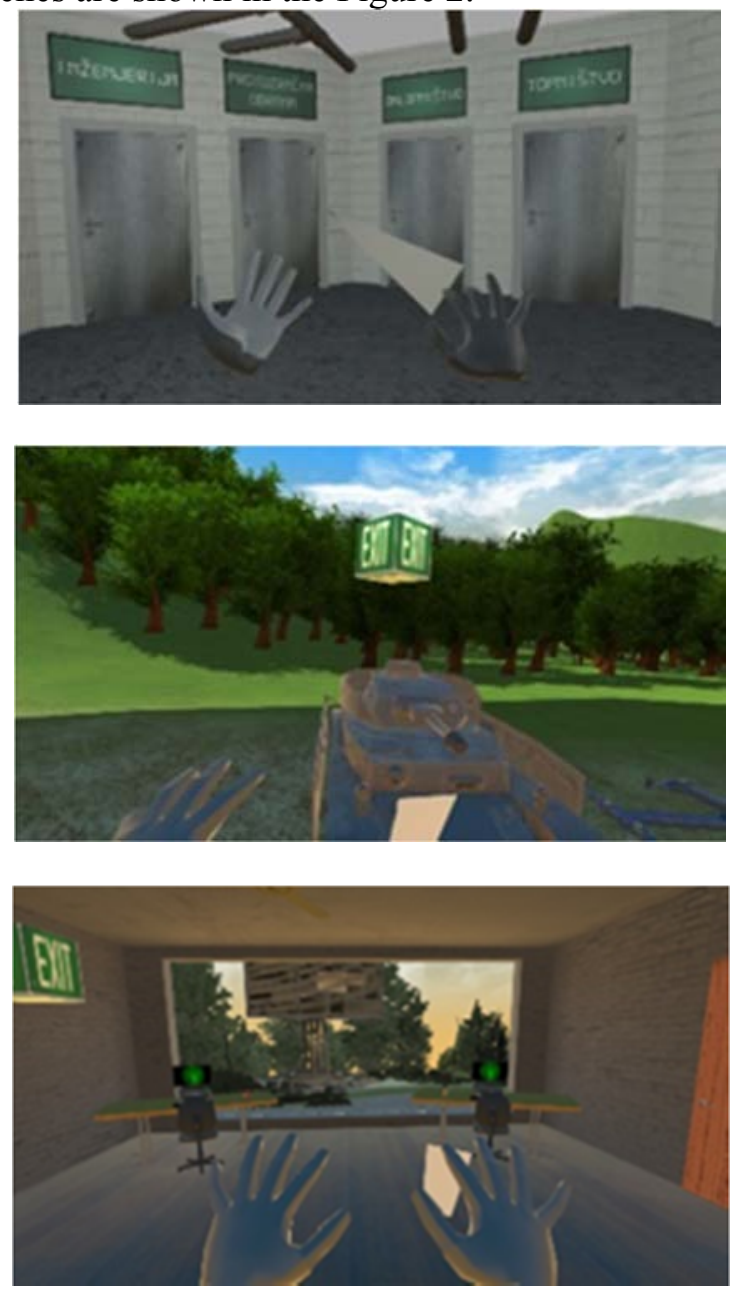

Fig. 2. Scenes from the application for military unit presentation

The aim of the prototype application is to introduce available military units to cadets in the form of the serious game based on VR. Military units are presented by using specific unit objects selected based upon the information provided by cadets from these units [18]. By interacting with these objects, users are introduced to the specifics of each military unity.

The VR prototype development process was as follows: Initial idea was proposed by two cadets during their undergraduate final work [19]. The idea was described and presented as a low-fidelity prototype.Then student project was initiated containing the team of 4 students and 2 teachers from the field of engineering and computing, with the duration of 15 weeks, which resulted in application prototype based on VR and developed in technological platform Unity. Key input information for the prototype were provided by undergraduate cadets at the 4th year of military academy who were not specifically trained to VR environments and most of them had not any experience in using it. 
Cadets participate in the design of the application scenes by providing list of objects to be displayed.

They provided information about prototype based on their own experience related to the military unit they belong. After the prototype was finished and functionally tested, an evaluation in research year 1 was organized at military academy.A user survey was conducted with cadets who participated in the development process and actually performed user testing of developed prototype, and with military professionals who took the role of evaluation experts. The objective was to evaluate:

- the overall user's level of satisfaction with the developed VR prototype application, with focus on designed scenes and used interaction techniques in the virtual environment.

- prototype usefulness in terms of its future use in cadet education, focusing on technical improvements and general concept of VR serious game applications.

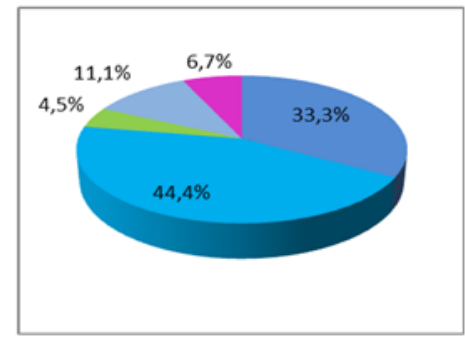

(a) Application is easy to use

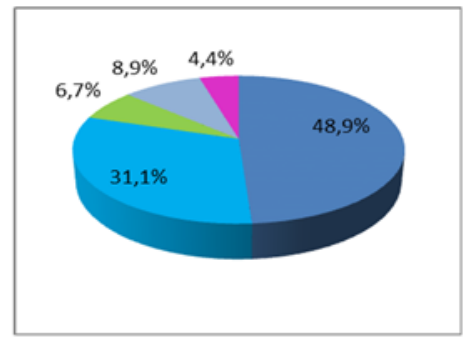

(b) Application is interesting

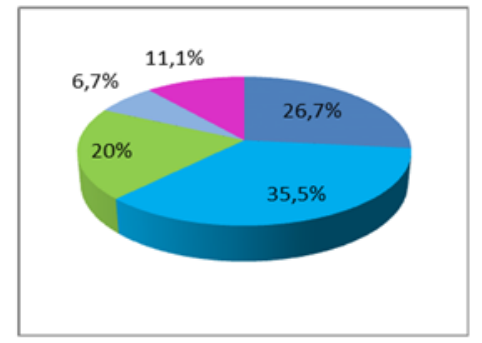

(c) Application is useful for military unit presentation evaluation process total of 40 participants were involved, from which $87 \%$ were cadets. Each participant individually used the application with the following evaluation scenario:

- group presentation of application functionalities

- individual free use of application (in order to get feeling of interactions and virtual environment since the most participants used VR for the first time)

- completing given task - with the support of evaluation moderator (person who monitors evaluation and provides key inputs to users) participants should have visited two selected military units, interacted with specific objects and used two different motion in virtual environment (tunneling and teleportation).

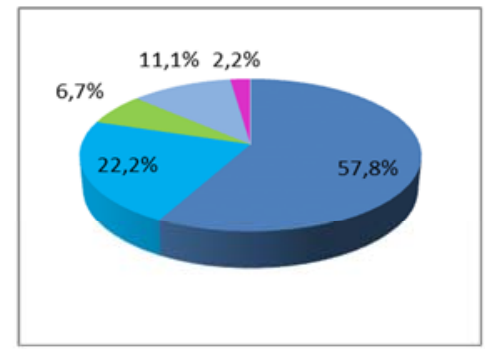

d) I felt comfortable while using it

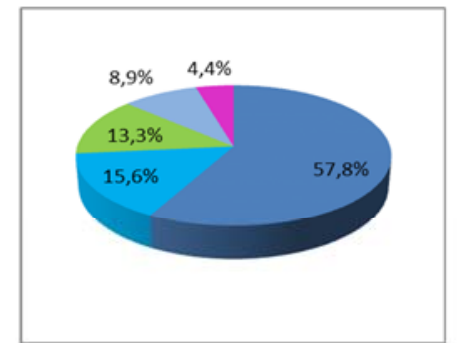

e) I felt comfortable during tunneling

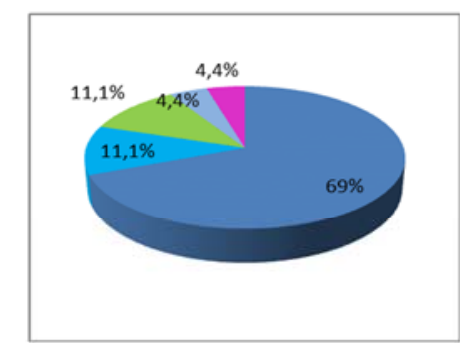

(f) I felt comfortable during teleportation
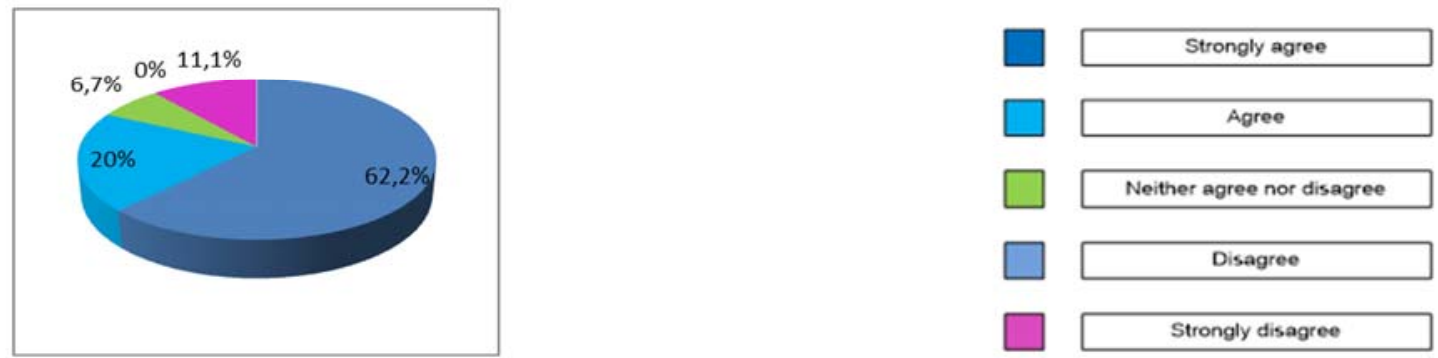

g) I like the concept of emerging and interacting with virtual world

Fig. 3. Evaluation survey results for VR prototype and cadet generation 2019 
In order to measure user satisfaction with VR education prototype, the Likert scale questionnaire was used. Every statement was rated with a grade from 1 to 5 , where 1 denoted strong disagreement, and 5 strong agreement with the statement.Evaluation question were about the following prototype features:

- usability

- attractivity

- usefulness

- user comfort during interactions

- general user experience with emerging into virtual environment.

Evaluation survey results for the generation 2018 are presented in [20]. Based on this result the application was slightly improved, mostly in the part with user interactions with the objects.In research year 2 new cadet generation was introduced to VR applications potential usage in military domain, but they were introduced within the lectures. Also, this generation had to complete several research tasks to get more knowledge about the VR application in military domain. Only after they participated in the evaluation of the VR prototype, the evaluation results are shown in the Figure 3.

As the Chart 3a shows, participants consider VR prototype easy to use with the average grade 3.86 possible argumentation for this could be that most of the participants were exposed to VR for the first time. Comparison of results for two generations: Average grade 2019, $\mathrm{n}=46 / 3,86$; Average grade $2018, \mathrm{n}=29 / 3,91$.

It can be seen in Figure $3 \mathrm{~b}$ that $48.9 \%$ of participants consider application interesting. The average grade is 4.11 (in previous evaluation: 4.25). A slight decrease of this grade is present. Suitability of the application for presenting military units is rated with an average grade of 3.6 (Figure 3c). Although $11.1 \%$ of the cadets strongly disagree with usefulness of application, one third of them strongly agrees that the application presents military units well. Comparison of results for two generations: Average grade 2019, $\mathrm{n}=46 / 3,6$; Average grade $2018, \mathrm{n}=29 / 3,78$.

Statements about movement in the virtual reality showed no difference between level of comfort while using tunneling and teleportation. The overall comfort of using the application is rated with an average grade of 4,22 (Chart 6d) Comparison of results for two generations: Average grade 2019, $\mathrm{n}=$ 46 / 4,22; Average grade 2018, $\mathrm{n}=29 / 3,94$. Tunneling motion is rated with an average grade of 4.13 , while the teleportation is rated with an average grade of 4.33. Both generation of cadets did not find tunneling more nauseous than teleportation.

When comparing results regarding tunneling (Chart 6e) and teleportation (Chart 6f), it can be seen that they only slightly differ in distribution of "Neither agree nor disagree" and "Agree" answers.On the basis of the above, it can be concluded that the cadets did not find tunneling more nauseous than teleportation.

The concept of emerging and interacting with virtual world is rated with an average grade of 4.22. (Figure 3g). Comparison of results for two generations: Average grade 2019, $\mathrm{n}=46 / 4,22$; Average grade 2018, $\mathrm{n}=29 / 4,22$. According to the results of the prototype user evaluation, cadets showed overall satisfaction with the application, usable and comfort.

\subsection{Researching potential of AR technology in improving key cadets skills}

After presenting VR prototype, AR technology was introduced to cadets as well as AR application functional prototype for presenting possible functionalities of AR interactions for the example of tank, military vehicle and weapon (Figure 4).

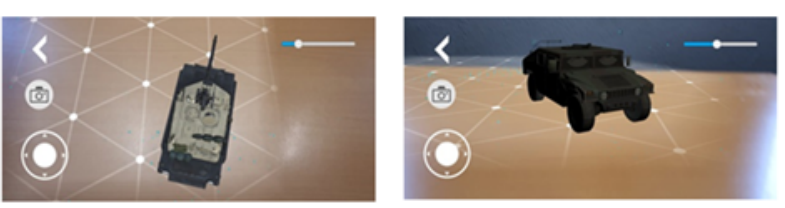

Fig. 4. AR prototype application scenes (tank and vehicle)

After presenting the prototype and individual use of it, cadets were given a task to reflect on capacity of AR technology for improving interpersonal, technical and conceptual skills. The obtained results were as follows:

\subsection{Improving interpersonal skills by utilization of AR}

In armor and logistics domain - user could have to complete specific tasks on a tank model, vehicle and a specific type of weapon (familiarizing in this way with the tank structure, vehicles and weapons) or issue an operating order to start the action in front of the audience. In addition, VR gloves would be used for operating on the sandbox (model technical means). In this way instructor and other cadets can give quality feedback to the user.

\subsection{Improving technical skills by utilization of $\mathbf{A R}$}

In military engineering - by using AR glasses and data gloves user works to operate tanks, vehicles 
and weapon. Namely, VR glasses can give cadets virtual augmented reality where the tank, vehicle, and armaments all have real parts and are no different in physical appearance from real ones.Also, in virtual reality, it is crucial that cadets perceive that they have the necessary protective clothing intended for this work (helmet, protective suit and gloves). Furthermore, using gloves, cadets could disassemble parts to the smallest detail, just as they would in reality. Doing that way, it is important that the tank, vehicle, and armaments in the virtual reality are identical to the ones in the real world, including dimensions, the relationship of dimensions and positions of separate parts, the force required to disassemble or assemble separate parts, and the similarity. Also, this is a much cheaper way of training and the immeasurable advantage of this type of training is safety and the absence of risk, since once a system is developed it only requires maintenance and upgrades when the need arises, as opposed to acquiring a sufficient amount of real assets.

\subsection{Improving conceptual skills by utilization of $\mathbf{A R}$}

In view of the contemporary threats that are taking place in the urban environment, AR could be used to train a faster process in eliminating the technical malfunctioning of a tank, vehicle and weapon. In doing so, the cadets would perceive which parts or elements of the system were defective to be replaced using AR glasses. Also, VR gloves would be used to rehearse the procedures when changing parts (tank, vehicle, weapon). More situations would come up where, at an initial stage, it would be easy to figure out problem. After applying this method of training, it would start over and each of the above situations would reappear, given a different space and other problems to solve.Figures $5 \mathrm{a}, 5 \mathrm{~b}$ and $5 \mathrm{c}$ showing cadets' satisfaction with using a tank, vehicle, and weapon assets within AR prototype.

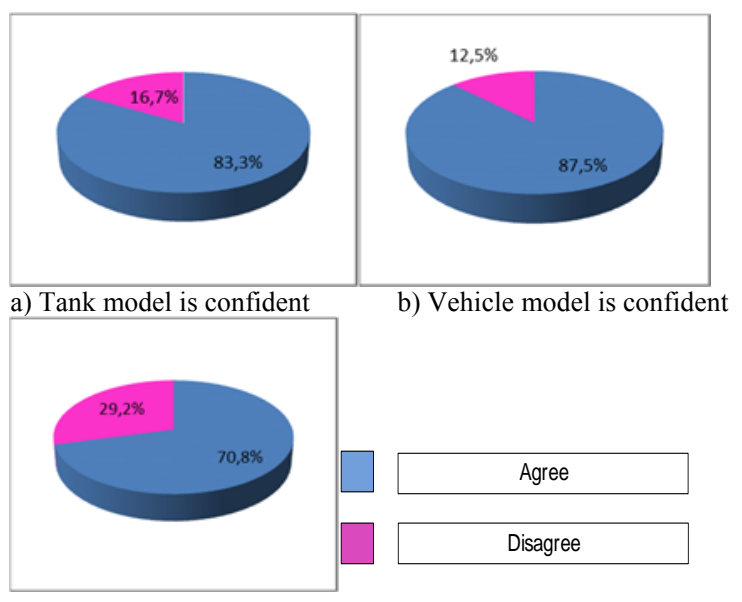

c) Weapon model is confident

Fig. 5. Evaluation survey results for AR

\section{Conclusion}

Even during the Sun Tsu era, while there was talking of a way of warfare, in order to win a war, the development of war games began, which has continued to this day. Simultaneously with the development of war games, simulations have also evolved. While serious games today can be said to have a much broader character and simpler purpose, they were initially designed to train people for tasks in certain jobs and were mainly about acquiring knowledge and / or procedural skills. It is important that every serious game in the foreground has an educational purpose, not entertainment. Following this trend, the proposal of a serious game created in the course of this paper, entitled "Choosing Directions for Future Commanders of Military Teams," aims to educate young cadets, or future commanders. It is a serious game theoretically designed to improve the communication aspects of the focus placed on the future commander of military teams.

Emerging technology, such as AR and VR has a great potential of utilization in military education. Although there are numerous solutions in this field, they are under-researched. During the research described in the paper, AR and VR prototypes were developed, with several purposes: to introduce cadets to these technologies, to add value to education given the content of the prototypes, and to motivate in a structure way both cadets and military professionals to reflect about future potential beneficiaries of solutions. Their active involvement in the process of developing any future education solutions based on emerging technology is prerequisite since they can provide valuable software requirements and ideas how the direct solution design and content to be useful and increase military capacity in terms of improvement of education, interpersonal, technical and conceptual skills. As with any new technology, it is hard for user to reflect on something that has not been in use, so the prototyping and evaluation methodology applied in this research provided structured way of fast-tracking introduction of user to the emerging technology features.

\section{References:}

[1] I. S. Pandzic, T. Pejsa, K. Matkovic, H. Benko, A. Cerekovic, and M. Matijasevic, Virtual Environments: Interactive graphics 3DElements,2011. 
[2] G. C. Burdea and P. Coiffet, Virtual Reality Technology. John Wiley\& Sons Inc., 2003.

[3] E. E. Jerković, Oculus Rift, type of article, University of Zagreb, FER, Zagreb, 2015.

[4] A. Lele, "Virtual reality and its military utility," Journal of Ambient Intelligence and Humanized Computing, vol. 4, 022011.

[5] A. Rizzo, J. Pair, K. Graap, B. Manson, P. J. McNerney, B. Wiederhold, M. Wiederhold, and J. Spira, "A virtual reality exposure therapy application for iraq war military personnel with post traumatic stress disorder: From training to toy to treatment," NATO Advanced Research Workshop on Novel Approaches to the Diagnosis and Treatment of Posttraumatic Stress Disorder, 01. 2006.

[6] T. Matković, Playing war? War Games in Civil and Military Use, originalscientific, paper, Faculty of Philosophy, University of Zagreb, Zagreb, 2003.

[7] A. De Gloria, F.Bellotti, R. Berta, E. Lavagnino, Serious Games for education and training(2016), ResearchGate,Genova, https://www.researchgate.net/publication/2862 44094 (28-04-2020)

[8] I. Didaković, Training Simulations in the CAF (2001), master thesis, Ministry of Defense CAF, Military Academy, CSS "BlagoZadro", Zagreb

[9] D.Ivković, Center for Combat Simulations in Training Command and Troops, AFBiH (2014.), master thesis, Ministry of Defense CAF, Military Academy, CSS "BlagoZadro", Zagreb

[10] E.Kai, The Impact of Gamification Recommending Education Scenarios. International Journal of Emerging Technologies in Learning (iJET).https://www.researchgate.net/publicatio n/274775610_The_Impact_of_Gamification_Recommending_Education_Scenarios, 2020.

[11] Z. Jakop, D. Tušek, M. Hajsok, Trainig simulations and simulation models, Ministry of Defence CAF, Zagreb 2006.
[12] M. Puhalović, The Application of Virtual and Augmented Reality in the Military Domain, Seminar, University of Zagreb, FER, Zagreb, 2018.

[13] E. Malbos, L Boyer, C. Lançon, "Virtual reality in the treatment of mental disorders", (article in French) "L'utilisation de la réalitévirtuelle dans le traitement des troubles mentaux", La Presse Médicale, Volume 42, Issue 11, November 2013, pp 1442-1452

[14] A. Rizzo, M.J. Roy, A. Hartholt, M. Costanzo, "Virtual Reality Applications for the Assessment and Treatment of PTSD", Handbook of Military Psychology: Clinical and Organizational Practice (pp.453-471)

[15] S. Holister, "Blueshark: Where the US Navy dreams up the battleship interfaces of tomorrow", 2014.

https://www.theverge.com/2014/1/26/5346772/ blueshark-us-navy-oculus-rift-virtual-interface, (01-11-2019)

[16] R. McAlinden, "One World Terrain (OWT)",2013.http://ict.usc.edu/prototypes/one -world-terrain-owt/, (01-12-2019)

[17] I. Gače et al. "A Serious Game VR Prototype for Learning about Military Units based on Unity Platform (project report)", University of Zagreb Faculty of Electrical Engineering and Computing, 2018.

[18] Ivana Ivanda et al. "An AR Prototype for Military Academia (project report)", University of Zagreb Faculty of Electrical Engineering and Computing, 2019.

[19] P. Antolovic, "Application of Virtual Reality in the Military Domain,"BSc Thesis, University of Zagreb Croatian Military Academy "Dr. Franjo Tudman", 2018.

[20] P.Kolas,"Military Teamwork Improvement Based on The SeriousGames Application," BSc Thesis, University of Zagreb Croatian Military Academy "Dr. Franjo Tudman", Zagreb, 2018.

\section{Creative Commons Attribution License 4.0 (Attribution 4.0 International, CC BY 4.0)}

This article is published under the terms of the Creative Commons Attribution License 4.0 https://creativecommons.org/licenses/by/4.0/d eed.en US 